NBER WORKING PAPER SERIES

\title{
THE IMPORTANCE OF THE MEANING AND MEASUREMENT OF “AFFORDABLE” IN THE AFFORDABLE CARE ACT
}

\author{
Richard V. Burkhauser \\ Sean Lyons \\ Kosali I. Simon \\ Working Paper 17279 \\ http://www.nber.org/papers/w17279 \\ NATIONAL BUREAU OF ECONOMIC RESEARCH \\ 1050 Massachusetts Avenue \\ Cambridge, MA 02138 \\ August 2011
}

Acknowledgments: The authors acknowledge receiving partial funding for this study from the Employment Policies Institute, in the amount of a total budget of $\$ 40,000$. We are grateful for helpful conversations with several individuals, including Chrissy Eibner, Phil Ellis, Doug Holtz-Eakin, Jenny Kenney, Richard Kronick, and Mike Saltsman. Conflict of Interest Statement: During the last three years, the authors have worked as paid consultants for the Pew Charitable Trust (Burkhauser and Simon), and the Center for American Progress (Simon) on research related health reform. The views expressed herein are those of the authors and do not necessarily reflect the views of the National Bureau of Economic Research.

NBER working papers are circulated for discussion and comment purposes. They have not been peerreviewed or been subject to the review by the NBER Board of Directors that accompanies official NBER publications.

(C) 2011 by Richard V. Burkhauser, Sean Lyons, and Kosali I. Simon. All rights reserved. Short sections of text, not to exceed two paragraphs, may be quoted without explicit permission provided that full credit, including $\odot$ notice, is given to the source. 
The Importance of the Meaning and Measurement of "Affordable" in the Affordable Care

Act

Richard V. Burkhauser, Sean Lyons, and Kosali I. Simon

NBER Working Paper No. 17279

August 2011, Revised September 2011

JEL No. I0

\begin{abstract}
This paper focuses on the practical importance of a critical but under-explored interpretation of a provision in the Affordable Care Act (ACA): whether "affordable" refers to the cost of single coverage alone, or to family or single coverage as applicable to the worker, in determining the employer's mandated coverage requirement and workers' (and their dependents') access to subsidized exchange coverage. Since the average annual total premium for family coverage is substantially higher than that for single coverage (on average $\$ 12,298$ vs. $\$ 4,386$ in 2008) this is a non-trivial distinction.

Using data on workers from the Current Population Survey merged with estimates of employer and exchange policy premiums, we investigate the impact of the affordability decision on the fraction of workers who could then access exchange coverage subsidies and on the correspondingly lower employer sponsored insurance (ESI) coverage rates. We do via a series of calculations for each worker that first shows the financial incentives at stake in deciding between ESI and subsidized exchange coverage. We then show how many of those who stand to gain from exchange coverage could do so under the two different affordability rules and different levels of employee contributions. Finally, we show the extent to which a single affordability rule would cause low-income workers with families to fall into a "no-man's land" with no source of affordable family coverage.
\end{abstract}

We estimate that choosing a family affordability rule could initially lead to as many as 1.3 million more workers accessing exchange subsidies for themselves and their families than under a single affordability rule. If employees pay 50 percent of the premiums in the future, this number increases to 6 million. Increased use of exchange subsidies would be accompanied by reductions in ESI coverage and increased costs to taxpayers. Alternatively, choosing a single affordability rule would initially result in close to 4 million dependents of workers with affordable single coverage not having affordable health insurance. This would grow to close to 13 million if employees pay 50 percent of the premium. [?

Richard V. Burkhauser

Cornell University

Department of Policy Analysis \& Management

125 MVR Hall

住haca, NY 14853-4401

and NBER

pvb1@cornell.edu

[?

Sean Lyons

PhD candidate

Dept. of PAM

Cornell University, Ithaca NY

sml55@cornell.edu

]

An online appendix is available at:

http://www.nber.org/data-appendix/w17279
एᄄKosali I. Simon

mSchool of Public and Environmental Affairs

UIIndiana University

एाRm 359

س1315 East Tenth Street

mBloomington, IN 47405-1701

mand Cornell University

mand also NBER

msimonkos@indiana.edu 


\section{Introduction}

The Affordable Care Act (ACA) ${ }^{1}$ represents a major change in the provision and organization of health insurance in the United States, using four primary strategies: an expansion in Medicaid to low-income adults, a series of sliding scale subsidies for other low to middle income families, fines for certain employers and individuals who do not offer or obtain coverage, and a restructuring of and reforms to the individual health insurance market to create health insurance “exchanges”. Under the ACA, low- to middle- income families are eligible for subsidized exchange health insurance only if employer coverage is not offered or is offered but not considered affordable, thus forming a "firewall” (CBO, 2010) that prevents unintended movement out of employer-sponsored insurance (ESI) towards subsidized exchange coverage. For ESI to be considered "affordable" under the ACA, the employee portion of the premium must not exceed 9.5 percent of household income. If employers do not offer coverage or offer unaffordable coverage and employees receive subsidized coverage through the exchange, large employers with more than 50 full-time equivalent workers are subject to fines. The unresolved question we investigate in this paper is whether the firewall condition refers to the cost of single coverage alone (henceforth referred to as the "single” definition), or to family or single coverage as applicable to the worker (henceforth referred to as the "family" definition).

The ACA is expected to substantially expand health insurance coverage to uninsured Americans. However, there are also various aspects of the law that could have unintended effects on employer and employee behavior. One concern that has been raised is that firms may drop

\footnotetext{
${ }^{1}$ The full text of the Patient Protection and Affordable Care Act of 2010 (P.L.111-148) can be found at http://frwebgate.access.gpo.gov/cgi-bin/getdoc.cgi?dbname=111_cong_bills\&docid=f:h3590enr.txt.pdf and the Health Care and Education Reconciliation Act of 2010 can be found at http://frwebgate.access.gpo.gov/cgibin/getdoc.cgi?dbname=111_cong_bills\&docid=f:h4872enr.txt.pdf More detailed reviews of the ACA provisions for employers can be found elsewhere, including Simon (2010).
} 
coverage so that their workers can take advantage of the public subsidies for health insurance provided through the exchanges (Adamy, 2011). If the firm's employees are drawn from both lower and higher income households, however, dropping coverage might benefit lower income workers, but would likely make higher income workers worse off because those over 400 percent of the federal poverty line are not eligible for exchange subsidies under the ACA. Therefore, they would lose the tax advantages of ESI coverage and potentially face more costly premiums in non-employer purchasing arrangements because of higher administrative costs or adverse selection in the exchanges. Since non-discrimination laws prevent firms from offering ESI coverage to their higher income workers without also doing so for their lower income workers, the incentives to drop coverage are likely to be low for employers with a heterogeneous workforce. However, while such employers may not drop coverage, the subsidies could induce strategic behavior to change labor contracts in other ways (Kessler, 2011, McKinsey Quarterly, 2011).

In this paper, we study the importance of defining affordability by the single or family coverage standard for estimates of exchange and ESI coverage, and for lower income workers' ability to find affordable family coverage. This analysis is especially important since it provides information to policymakers as they consider the affordability decision during the law's implementation stage. We use household survey data from the Current Population Survey (CPS) merged with employer health insurance data from the Medical Expenditure Panel Survey Insurance Component (MEPS-IC) and exchange premium estimates from the Kaiser Family Foundation (KFF) Web site to perform calculations of potential gains and losses for workers and their firms if affordability is defined by the single or by the family option. 
Since the exchange vs. ESI decision is most relevant for workers who fall into the income range potentially eligible for subsidies and who either have current ESI coverage in the CPS or would be affected by the employer mandate under the ACA, we perform our calculations of potential incentives for this subsample of workers. ${ }^{2}$ These calculations assume the worker bears the full employer's cost of health insurance through reduced wages, and take into account the tax benefits to ESI and the ACA fines that large employers would pay if workers receive subsidies. The calculations identify the workers for whom there is "money on the table" (potential financial gains to switching into exchange coverage) created by the availability of exchange subsidies. We present stylized cases to answer the following question: what fraction of those with "money on the table" would be classified as having unaffordable coverage under the single vs. the family definition of affordability? The answer also depends on the way that employers set the employee contributions to health insurance. However, the willingness and ability of workers and firms to act on these financial incentives depend on several other factors outside our calculations. For example, it is uncertain how attractive exchange plans will appear relative to ESI plans. It is also uncertain how ESI plans will change in the future as a consequence of rising health care costs. As a result, our first goal is to present a stylized range of estimates that illustrate the possible importance of the affordability definition on exchange and ESI coverage rates.

Since the average annual total premium for family coverage is roughly $\$ 8,000$ higher than that for single coverage ( $\$ 12,298$ vs. $\$ 4,386$ in 2008 , shown in Table 1 ), there is the potential for substantially more families to obtain subsidized coverage through the exchanges if affordability is based on family coverage, if employee premium contributions are set sufficiently

\footnotetext{
${ }^{2}$ The workers who are potentially eligible for subsidies are those in families with incomes in the range of 133 to 400 percent of the poverty line. Four times the poverty line is $\$ 84,800$ for a family of four in 2008 . The workers who fall under the employer mandate rule are full time workers in firms with more than 50 employees.
} 
high. ${ }^{3}$ The affordability definition could significantly impact the ability of lower income workers' dependents to find affordably-priced coverage if single ESI coverage is affordable but family ESI coverage is not. Thus, as the second component of our analysis, we show the consequence of adopting the single affordability definition on the number of low-income workers with families that would find themselves in a "no-man's land" with no source of affordable family coverage. When ESI single coverage is affordable, both the worker and dependents would be restricted from receiving exchange subsidies, regardless of how unaffordable family ESI coverage might be.

Hence, we estimate that choosing a family affordability rule could initially lead to as many as 1.3 million more workers accessing exchange subsidies for themselves and their families than under a single affordability rule. If employees pay 50 percent of the premiums in the future, this increases to 6 million. Increased use of exchange subsidies would be accompanied by reductions in ESI coverage and increased costs to taxpayers. Alternatively, choosing a single affordability rule would initially result in close to 4 million dependents of workers not having affordable health insurance from any source. This would grow to close to 13 million if employees pay 50 percent of the premium.

Our paper proceeds as follows. We first review the reasons why the definition of affordability in the ACA is ambiguous. Second, we present a simple example of why this definitional choice for affordability has meaningful consequences for workers and their families and how the consequences vary with the level of employee contributions to health insurance premiums. Next, we review the prior relevant literature and present our conceptual framework and calculations. We then describe our data set construction, methods, and results. We conclude

\footnotetext{
${ }^{3}$ Single individuals between 133 percent and 400 percent of the poverty line who have no dependents or whose dependents are all covered by existing public insurance programs (CHIP) are not affected by the affordability decision since the applicable definition of affordability for those workers is single coverage.
} 
with a discussion of the limitations and implications of our results for future policy simulations of the ACA's consequences for subsidized exchange insurance for lower income families.

\section{The Source of Ambiguity Regarding the ACA Definition of Affordability}

While it is clear that the ACA considers an offer of ESI to be affordable if it costs less than 9.5 percent of gross household income, it is unclear whether this refers to the premium for single coverage or family coverage as applicable to the workers, or whether it always refers to single coverage. The Senate Finance Committee report published on October 18, 2009, upon which the eventual ACA legislation was based defined affordability as follows: "Unaffordable is defined as coverage with a premium required to be paid by the employee that is ten percent or more of the employee's income, based on the type of coverage applicable (e.g.. individual or family coverage)." (Underline added, U.S. Senate, 2009, p.39). Between October 18, 2009 and December 24, 2009 when the final bill was passed by the Senate, the language that defines affordability was changed with the word "self-only coverage" substituted for "the type of coverage applicable (e.g., individual or family coverage)". Because the House of Representatives accepted as a whole the language in the Senate bill, in the final version of the ACA legislation passed by both Houses and signed by President Obama affordability is defined in section $5000 \mathrm{~A}(\mathrm{e})(1)(\mathrm{B})$ as:

“(B) REQUIRED CONTRIBUTION.—For purposes of this paragraph, the term 'required contribution' means-

(i) in the case of an individual eligible to purchase minimum essential coverage consisting of coverage through an eligible-employer-sponsored plan, the portion of the annual premium which 
would be paid by the individual (without regard to whether paid through salary reduction or otherwise) for self-only coverage” (underline added).

The Congressional Budget Office (CBO) and the Joint Committee on Taxation (JCT) used the definition of single coverage in scoring the bill, following the language in Section $5000 \mathrm{~A}(\mathrm{e})(1)(\mathrm{B})$ of the ACA. Under this interpretation, families will receive premium subsidies on the exchanges based on income only if they were not offered ESI coverage at all or if the firm offered coverage to them but the "single option", as opposed to the "family option" was unaffordable. $^{4}$

However, language in other parts of the ACA still refers to coverage for families as well. For example, Section 1513 describes the shared responsibility clause that triggers a fine as occurring when a “... large employer fails to offer to its full-time employees (and their dependents) the opportunity to enroll in minimum essential coverage..." The section further stipulates that a large employer that has offered its “...full time employees (and their dependents) the opportunity to enroll in minimum essential coverage...” but nonetheless has one or more of its full time employee enroll in an exchange plan and receive a subsidy will trigger a different fine. (Underline added).

This ambiguity about whether the affordable coverage rule applies to single coverage or family coverage for workers with families is scheduled to be resolved through a proposed implementation rule announced August $12^{\text {th }} 2011$ by the Department of Health and Human

\footnotetext{
${ }^{4}$ Families will also receive premium subsidies if the offered coverage did not meet minimum essential coverage guidelines and was less than 60 percent in actuarial value; Section 1512 stipulates this happens " if the employer plan's share of the total allowed costs of benefits provided under the plan is less than 60 percent of such costs". Since we do not know the actuarial values of current plans, this is not a feature of the law that we study. We also ignore a provision regarding "free choice vouchers" that was repealed as part of the 2011 budget act, (§1858 of H.R. 1473, Department of Defense and Full-Year Continuing Appropriations Act, 2011).
} 
Services, with hearings set for November $17^{\text {th }} 2011 .^{5}$ The proposed rule is to use the single definition of affordability.

Before we describe our conceptual framework and empirical approach in detail, we illustrate the importance of the definition of affordability and the employee contribution level in the context of three hypothetical families that each contains one worker and three dependents (Table 1). In column 1, we list the annual, before-tax income of these three families that earn 133 percent, 250 percent and 400 percent of the federal poverty line respectively. Their income values span the full income range for exchange subsidies. Columns 2 and 3 display the total average national premiums for single and family coverage. Our ESI prices are based on the 2008 Medical Expenditure Panel Survey-Insurance Component (MEPS-IC). The national average total premium for single coverage in 2008 is $\$ 4,386$ (column 2) and the national average employee premium amount is $\$ 882$, thus the average national employee contribution share for single coverage is 20.1 percent. The national average total premium for family coverage is $\$ 12,298$ (column 3) and the corresponding employee premium is $\$ 3,394$, thus the employee share for family coverage is 27.5 percent. Column 4 shows the typical amount of subsidy each of these families would receive towards exchange coverage, calculated from the Kaiser Family Foundation (KFF) exchange premium calculator. ${ }^{6}$ The amount of money the worker would actually gain in cash compensation would be lower than the subsidy by the amount of the

\footnotetext{
${ }^{5} 45$ Code of Federal Regulations (CFR) Parts 155 and 157, Department of Health and Human Services (DHHS), available at http://www.ofr.gov/(X(1)S(cjrlex1mz20ayk4j1n3szdny))/OFRUpload/OFRData/2011-20776_PI.pdf,, accessed August 2011.

${ }^{6}$ Subsidies are calculated by obtaining the predicted exchange premium from the KFF calculator, and then following the legislative language that caps out of pocket premium spending according to the relevant level of income as a percent of the poverty level. The remainder is the subsidy, a refundable and advanceable premium tax credit provided by the government. We do not take additional cost sharing subsidies into account.
} 
employer fine; the fact that ESI premiums are tax exempt while any out of pocket payments to exchange coverage are not is also later taken into consideration. ${ }^{7}$

Column 5 of Table 1 shows that if employers keep employee contributions at the current national average level of 20.1 percent for single coverage, the average contributions of workers for single coverage never exceed 9.5 percent of family income. Hence if the affordability definition for access to exchange subsidies is affordable single coverage, and if employee contributions do not change, none of our Table 1 families would be eligible for an exchange subsidy even if their family ESI coverage was unaffordable. While the worker would have affordable single coverage, his or her dependents would be in a “no-man’s land” with unaffordable ESI family coverage and no access to exchange subsidies despite meeting the income criteria for such coverage. ${ }^{8}$ If employers keep employee contributions at the current level of 27.5 percent for family coverage, the family ESI contributions of our workers living in families with income of 250 and 400 percent of poverty also do not exceed 9.5 percent of their income (Column 6 of Table 1). Hence, they and their families would not be eligible for an exchange subsidy even using the family affordability rule because their ESI family coverage is affordable. But the worker with family income of 133 percent of poverty would now be eligible for an exchange subsidy even though the worker's single coverage was affordable. Hence when the family affordability criterion is used, no dependents will ever find themselves in "no-man’s land”. But the tradeoff in this example is that the exchange subsidy firewall will be breached by

\footnotetext{
${ }^{7}$ The tax advantage provided to ESI is estimated to result in \$1.1 trillion in foregone tax revenue in 2012-2016 (Fronstin, 2011).

${ }^{8}$ In this simplified exercise, we do not take into account the availability of CHIP coverage for children in some families earning above 133 percent of poverty. When using micro data to calculate the number of dependents who do not have access to affordable coverage, we take into account the CHIP eligibility rules present in each state in 2008.
} 
the lowest income worker, who would have an incentive to seek exchange subsidized insurance for his or her family despite having an offer of affordable single ESI.

Columns 7 and 8 show how the ability to breach the firewall depends on the employee contribution to health insurance. In this extreme case, we assume labor contracts are renegotiated so that the worker will pay 100 percent of the ESI premium. In column 7 we see that even when a single affordability definition is used, the worker living in a family with income at 133 percent of the poverty line now pays more than 9.5 percent of that income in ESI premiums. Hence that worker and his/her dependents can gain access to exchange subsidies. In column 8 the firewall breach is even greater as all our families qualify as having unaffordable ESI coverage using the family affordability definition, and gain access to exchange subsidies. Although not shown in Table 1, an employer is fined for not offering affordable coverage. However, at $\$ 3,000$ or $\$ 2,000$ a worker, the fine is low relative to the cost of family health insurance. These simple hypothetical examples in Table 1 illustrate how the ability of families to claim unaffordable coverage and access exchange subsidies depends on the definition of affordability (single or family) as well as the amount the employee contributes to ESI coverage, and motivates the analysis we perform with the micro data.

\section{Prior Literature}

A few existing studies comment on the potential effects of ACA features on health insurance outcomes, although none have studied the family vs. single affordability criterion. A set of papers have considered how consumers may view exchange coverage.

Dafny, Ho and Varela (2010) estimate that the value to consumers of choosing among the greater number of plan options that are likely to be available in exchanges relative to what is typically offered by an employer would be substantial, and between 10 percent and 40 percent of 
current employer health insurance contributions. Another paper relevant to understanding the take-up of exchange coverage is Abraham and Feldman (2010), who simulate the willingness to purchase individual market insurance for workers who currently have ESI but might be uninsured in the future for various reasons. They find that the majority of these workers would be willing to purchase individual exchange coverage. While this paper does not directly compare ESI to exchange coverage, it is relevant because it suggests that exchanges would be viable and stable markets because of the total number of customers they would draw.

Although exchanges may draw customers due to the greater product variety they offer, low income workers may face difficulty in accessing exchange subsidies because they are provided as tax credits based on past income, and because of the discontinuity families face between Medicaid and exchange subsidies at 133 percent of the poverty line (Sommers and Rosenbaum, 2011). Graves (2011) analyzes different ways in which the method of calculating and administering subsidies could be made easier for families. He estimates that errors in calculating subsidy amounts under the current proposed system could actually lead to greater participation in exchange coverage among lower income families.

Thus, while our calculations assume that employers and employees will view exchange coverage and ESI as equivalent forms of coverage, it is still unclear whether this will be the case. Uncertainty remains regarding the degree of competition, and the resulting prices and plan characteristics.

Aside from issues of exchange coverage, other recent papers study different insurance aspects of the ACA. For example, Pizer, Frakt and Iezzoni (2011) look at how the Medicaid expansion and the excise tax on high premiums (the "Cadillac tax") might affect insurance outcomes in the very long run. They forecast that the interaction between these two features of 
the ACA could lead to higher Medicaid participation and lower ESI coverage than otherwise predicted.

In addition to the academic literature relevant for understanding isolated and specific aspects of reform, reports from comprehensive models of the ACA exist that are able to make predictions based on a sophisticated approach that integrates all the complex aspects of the law. The most important of these is the model used by the CBO (CBO, 2007a) that estimates the number of Americans likely to be covered by specific provisions of the ACA over a 10-year horizon. The health insurance provisions of the ACA are estimated to increase the rate of insured, non-elderly Americans to between 92 percent and 94 percent (CBO, 2010) through a combination of different approaches. By 2019, CBO expects the number of people covered by ESI to be 3 million lower on net, as a result of an increase of ESI of about 6 to 7 million (mostly because of the individual mandate); a reduction of 8 to 9 million people with ESI due to firms dropping ESI offers; and a reduction of 1 to 2 million people who would drop ESI and obtain exchange coverage, both because they would be able to claim their current ESI was unaffordable and obtain subsidies for exchange coverage, and because of possible imperfect enforcement of the firewall rules.

Since the CBO's publication of its estimates of the ACA, Holtz-Eakin and Smith (2010) raised a question of whether there may be more employers who drop ESI than is assumed in the CBO (2010) model. Holtz-Eakin and Smith (2010) argue that the exchange subsidies in the ACA are so substantial that they will encourage employers and employees to change their labor contracts to gain access to the "money on the table”. By examining the possibility that employers may drop ESI, they abstract from whether affordability is defined by single or family coverage, and do not comment on the possibility that employers may change employee contributions as an 
alternative strategy. Using hypothetical workers, they point to stylized cases where it makes financial sense for large employers to drop health insurance coverage and pay the $\$ 2,000$ fine. They calculate that it is in the interest of large firms to only employ full-time workers living in families with income up to roughly 200 to 250 percent of the poverty line as that is the income range in which exchange subsidies are financially beneficial despite the loss of tax benefits and the \$2,000 fine that results from no longer offering ESI. The employers could then pay the workers higher wages than they were able to when providing ESI. Holtz-Eakin and Smith note that whether firms will actually fully adjust in this manner will depend on certain inflexibilities in the labor market, but that "the massive federal subsidies are money on the table inviting a vast reworking of compensation packages.” (Holtz-Eakin and Smith, 2010, p. 4.)

Unlike Holtz-Eakin and Smith, (2010) or the CBO (2010), we assume that no firms drop ESI coverage. We make this extreme assumption to highlight an alternative possibility through which workers and their employers can gain access to that "money on the table", by resetting the employer-employee sharing of the ESI premium within a firm..$^{9}$ In this case we show why lowwage workers may remain with their current employer after the ACA and become subject to higher premium sharing rules, rather than sort to exclusively low-income firms.

In July 2007, Massachusetts became the first state to implement a package of reforms that bears resemblance to the ACA. The fine for employers who do not provide insurance that is "fair and reasonable" (at most, 67 percent of the premium is contributed by the employee) is nominal. However, employers and employees may face less "money on the table" to reduce generosity of ESI than under the ACA because Massachusetts requires employers to pay a large

\footnotetext{
${ }^{9}$ In tables available upon request, we compare how our results would change if we assume no employers adjust employee premiums but they drop coverage as in the Holtz-Eakin and Smith (2010) case. We find that dropping coverage as in Holtz-Eakin and Smith (2010) results in larger reductions in ESI coverage than in any of our cases, although the difference between their case and our family affordability case with high employee premium contributions is relatively small.
} 
share of their workers' uncompensated care through the Health Safety Net (HSN)

(Commonwealth of Massachusetts, 2011). Papers analyzing the Massachusetts experience find no evidence in the general population that ESI has reduced in response to the law (Long and Masi, 2008, and Gruber, 2011) although there is some evidence that private coverage may have reduced among the hospitalized population (Kolstad and Kowalski 2010).

While early evidence from Massachusetts suggests that the ACA may not have a major impact on employer provided health insurance, a large literature on how public health insurance expansions have affected employer provided insurance coverage of children based on prior Medicaid or CHIP expansions suggests that some degree of substitution of coverage is possible. A review of the literature in CBO (2007b) concluded that "for every 100 children who gain coverage as a result of SCHIP, there is a corresponding reduction in private coverage of between 25 and 50 children.” (p.11-12) Thus it has been difficult for these earlier forms of public insurance expansions to target the uninsured exclusively, even though many states have included measures in their programs to discourage those with an available offer of ESI from joining CHIP (Gruber and Simon, 2008).

\section{Conceptual Framework}

In our calculations we focus on behavioral changes that occur among workers living in families potentially eligible for exchange subsidies. Workers in families earning between 133 to 400 percent of the poverty line are assumed to weigh their options between ESI and exchange coverage if they are either currently ESI policy holders in the CPS or if they are uninsured but would be affected by the employer mandate because they are full-time workers in large firms. ${ }^{10}$

\footnotetext{
${ }^{10}$ We assume that any uninsured workers in the CPS must incur a full wage reduction in order to receive ESI under the employer mandate. In reality, some of these uninsured workers were offered ESI although it is not recorded in
} 
We also consider being uninsured as an option. ${ }^{11}$ We assume workers consider costs and benefits in a stylized manner where they will find exchange coverage financially preferable if the net cost of obtaining that coverage is lower than the net benefits of foregoing their ESI offer, incurring the "employer mandate" penalty and losing the tax benefit given to ESI. This is captured by the expression:

$$
\text { [1] }\left[\left(\mathrm{P}_{\mathrm{x}}-\mathrm{S}_{\mathrm{x}}\right)\right]<\left[\left(\mathrm{P}_{\mathrm{f}}+\mathrm{P}_{\mathrm{e}}-\mathrm{F}_{\mathrm{e}}\right)(1-t)\right]
$$

Where the left hand side of the equation represents the cost of obtaining exchange coverage and the right hand side represents the benefits to foregoing ESI. $\mathrm{P}_{\mathrm{x}}$ is the total price charged in the exchange, $\mathrm{S}_{\mathrm{x}}$ is the subsidy, ${ }^{12} t$ is the marginal tax rate, and $\mathrm{P}_{\mathrm{e}}$ is the employee contribution to the ESI premium and $\mathrm{P}_{\mathrm{f}}$ is the firm's contribution to the ESI premium. $\mathrm{F}_{\mathrm{e}}$ is the employer fine $(\$ 3,000)$. The right hand side of the equation represents "the money on the table" that the employee or employer stands to save if he or she were to no longer receive ESI, assuming that the full employer saving is passed on through higher wages (as in, for example, Abraham and Feldman 2010). We also consider a case where this does not happen. ${ }^{13}$ The employer fine is

the CPS. These workers would find it cheaper than we assume to be covered by ESI. But by the logic of full ESI pass through to wages, they would have as much to gain from exchange coverage as our calculations imply. Thus, the assumption of wage pass through is important in forecasting employee behavior in the future.

${ }^{11}$ Although workers above and below this subsidy income range of 133 to 400 of the poverty line are not affected by the definition of affordability changing, we include them in our data set for some of our calculations to put the changes we examine in context. Individuals above 400 percent of the poverty line are treated in a similar manner as individuals between 133 and 400 percent of the poverty line, except that they would not qualify for exchange subsidies. Since the interaction of ESI and exchange coverage is the focus of our paper, we abstract from the ACA Medicaid expansion entirely by assuming all workers in families earning less than 133 percent of poverty are covered by Medicaid. We do this for convenience, and altering this assumption has no consequence for our main analysis.

${ }^{12}$ We take into account the fact that that if the worker were to drop ESI and receive a compensating wage differential, the subsidy would be recalculated in equilibrium, as family income would rise. This is a simplification as subsidies are first determined by past income, and corrected retrospectively for changes in current income. If workers are risk averse, they may undervalue subsidies because of the risk that they may have to pay them back if their income is higher than expected. Graves (2011) concludes that these errors in forecasting may increase the number of those who enroll in exchange coverage.

${ }^{13}$ If we assume that the employer controls the savings and only passes on to the worker the amount needed to induce the employee to obtain the exchange subsidy instead of ESI, we obtain the same results for coverage estimates. The only difference is that in this case, the firm receives the economic rents, and that the tax rate on corporate profits would be different than the tax rate on employee wages. A different case that we did not explore is one where 
triggered when a worker from a large firm elects subsidized exchange coverage, which is ultimately paid by the employee in the form of reduced cash wages. We initially consider the case where the employer mandate penalty and the loss of tax preference for ESI are the only costs to declining ESI and assume no affordability firewall exists. In this situation the gap between the right hand side and the left hand side of [1] being greater than zero $\left[\left[\left(\mathrm{P}_{f}+\mathrm{P}_{e}-\mathrm{F}_{e}\right)(1-\right.\right.$ $\left.t)]-\left[\left(\mathrm{P}_{\mathrm{x}}-\mathrm{S}_{\mathrm{x}}\right)\right]>0\right]$ represents a financial incentive to obtain subsidized exchange coverage rather than seek ESI. ${ }^{14}$ A negative number indicates that even though the worker would be potentially eligible for a subsidy, its magnitude is not enough to compensate for the loss of the financial benefits of ESI, and the fine if they work in a large firm.

Next, we add the firewall provision of the ACA into our analysis and consider the effect of increases in employee contribution levels on the extent to which workers are able to become eligible for subsidized coverage in an exchange. This firewall condition explicitly depends on $\mathrm{P}_{\mathrm{e}}$, the amount of the employee premium contribution, as a share of the total family income-it cannot exceed 9.5 percent. We view the decision to increase employee contribution levels $\left(\mathrm{P}_{\mathrm{e}}\right)$ while decreasing $\mathrm{P}_{\mathrm{f}}$ and increasing wages at the firm as a joint decision between workers and employers. As illustrated in Table 1, the effect of increasing $\mathrm{P}_{\mathrm{e}}$ on the workers ability to pass the affordability firewall is especially large if the affordability definition uses family coverage.

employers can only pass on a fixed proportion, say, $50 \%$ of the compensating wage differential. The literature finds that employer pass-through of premiums is likely to happen at a larger group level such as the firm, in the relatively short run, rather than the individual. It is unclear how the incidence may be in a longer time horizon such as ones typically used for ACA consideration. Nevertheless, the speed with which compensation packages adjust introduce transaction costs and dampened incentives to consider exchange coverage, which could lead to fewer workers choosing exchange coverage if full adjustment did not occur.

14 Since workers for whom ESI and exchange coverage are relevant choices also have the option of being uninsured, we perform a calculation to check if those who were uninsured to begin with would find being uninsured financially better even after reform. To do that, we calculate if the worker decides to be uninsured by:

[2] \{Cost of better outcome in [Equation 1] $\}>\left\{\left(\mathrm{F}_{\mathrm{i}}+\mathrm{d}\right)\right.$ (Income $\left.)\right\}$

where $\mathrm{F}_{\mathrm{i}}$ is the individual-level mandated fine, and $\mathrm{d}$ is 10 percent if the person is less than aged 35 and 20 percent if aged 35 or older. Income is family income. We find very few would prefer to be uninsured. This is consistent with findings in the literature, e.g. Abraham and Feldman (2011), showing high valuation for insurance by those who would otherwise be uninsured in the future. When we used alternate values of 5,10 , and 15 percent for $d$ for everyone, our results did not change in any meaningful way. 
In the short run, employer attempts to increase the employee cost sharing across the board so that lower-income workers can qualify for subsidies would be viewed unfavorably by higher income workers, unless the employer were able to convince workers that the corresponding wage increases simply offset the increased employee cost sharing. In the longer run, inflation, new job creation and old job destruction aid the process of adjusting employee contributions. Because Internal Revenue Service (IRS) rules allow both employers and employees to contribute to health insurance premiums on a pre-tax basis (as long as employers establish the necessary paperwork) the split between employee and employer contributions for health insurance can be viewed as largely artificial in the long run as long as wages are adjusted. 15,16

After calculating the financial incentive represented by the existence of subsidies under the ACA for families between 133 and 400 percent of poverty, [( $\left.\left.P_{f}+P_{e}-F_{e}\right)(1-t)\right]-\left[\left(P_{x}-S_{x}\right)\right]$, we first graph its distribution. This helps us understand how much "money on the table” exists that may incent employees and employers to re-negotiate their compensation packages in the long run. Next, we focus just on those workers who find themselves facing potential gains if they were to choose exchange coverage. We calculate what fraction of these workers can overcome

\footnotetext{
${ }^{15}$ The ability of small firms to provide health insurance usually depends on the fraction of eligible employees accepting coverage. Small employers tend to have low employee contributions to ensure high participation rates, an issue that does not concern large employers. Insurer practices in unregulated markets allow them to put restrictions on terms of sale such as this. When reforms are instituted in the insurance market, this may not matter. For example, small firm exchanges will offer guaranteed issue plans with modified community rated premiums that allow for limited age variation and tobacco use. These premiums will not depend on the participation rate. Thus, at the extreme, all employers could set the annual contribution just above 9.5 percent of the income of the highest family income worker to qualify for a subsidy $(\$ 88,900$, thus setting the family contribution at $\$ 8,454)$ and bypass the affordability rule.

Very few workers of firms with more than 50 workers are in situations where they do not have a premium conversion arrangement, by unpublished estimates provided by the Agency for Health Care Research and Quality. ${ }^{16}$ Consider the following simple example. Suppose that in the long run employers require $\$ 10,000$ as a contribution towards health insurance from employees and contribute $\$ 2,000$ as the employer contribution. Workers at the firm should be indifferent (i.e. they have the same take home pay and the same fringe benefit package) if the employer had instead decided to ask for $\$ 11,000$ as an employee contribution, but paid all workers at the firm $\$ 1,000$ extra. Since the change in employee contribution and the change in wage is across the board at the firm, it does not involve any assumptions about whether wage-fringe tradeoffs occur at the worker or firm level.
} 
the affordability firewall and obtain exchange coverage depending on different levels of employee contributions and, depending on whether we use a single or family definition of affordability. We also examine how these patterns differ by specific income ranges, and by whether the workers are in small or large firms.

As the second component of our analysis, we calculate how many low-income workers would find themselves with no source of affordable coverage for their families if a single coverage definition of affordability is adopted under the ACA. The number of such families in "no-man’s land" would depend on the premium contribution rule used by the employer. To

perform this calculation, we focus on those workers who find themselves facing potential gains if they were to choose exchange coverage, and who have dependents to insure. We then examine how many of these workers would find their ESI family coverage unaffordable, but their ESI single coverage affordable, and thus be unable to obtain subsidies in the exchange under the single affordability definition. We examine how the number of workers and dependents in this “no-man’s land" changes with increases in the employee contribution rule.

\section{Data Sources and Compilation of Dataset}

We conduct calculations to illustrate the importance of the definition of affordability using a nationally representative sample of the population from the 2009 March Current Population Survey (which contains data from 2008), merged with additional data from other CPS data sets and information on average health insurance premiums from the MEPS-IC and KFF. We limit our sample to private sector non-self-employed working age individuals (aged 17 to 64). When we consider the decisions of these workers, we take into consideration the relevant characteristics of their family (such as the number of dependents) and create family health 
insurance units, grouping parents and children under the age of 26 living in the same family together. We assign individuals to one insurance status rather than allowing them to hold multiple insurance types using a hierarchy explained in the data appendix. We merge data on health insurance costs (total premiums, as well as the employee and employer portions) from 2008 MEPS-IC public-use summary tables using state and firm size (above and below 50 workers), ${ }^{17}$ separately by single and other types of family plans. ${ }^{18,19}$ Our sample size of workers in the 2009 March CPS is 36,950, representing 95,496,817 workers. The estimate from the Bureau of Labor Statistics for the number of total workers in the United States is 139,817,000 in July $2009 .^{20}$ As expected, this is higher than our total since we limit the sample to be 17-64 year old private-sector non self-employed workers.

We obtain estimates of exchange premiums from the KFF exchange premium calculator. ${ }^{21}$ These estimates pertain to the Silver Plan, and are obtained by age group of the

\footnotetext{
${ }^{17}$ The March CPS asks individuals to report the size of their employer, and offers options of less than 10, 10-24, 2599, 100-499, 500-999 and 1,000 and over. For purpose of the law, an important cutoff point occurs with respect to firms with 50 workers, meaning that workers in the 25-99 category must be assigned to either the 25-50 or 51-99 firm size category. The MEPS-IC data show that of all firms with 25-99 workers, about half the workers are employed by firms in the 25-50 firm size category. Thus, we randomly assign half of the workers in the CPS 25-99 firm size category to the 25-50 firm size category and the rest to the 50-99 firm size category.

${ }^{18}$ In calculating ESI premiums, we create customized family plans rather than assume that employers would price all family sizes the same. We do this by obtaining the details for single coverage and the details for "employee plus one" coverage. We assume that the difference represents the marginal cost of an additional dependent. We then add multiples of this extra cost to a policy so that we obtain different family coverage types for families or 2, 3, 4, 5, etc. We have also conducted some sensitivity tests where we use a full family policy (as reported in the MEPS-IC data) regardless of how many dependents are present.

${ }^{19}$ We merge in average values as specific employer health insurance costs are not collected in the CPS. Current evidence shows that ESI generosity for low-wage workers depend substantially on the characteristics of their coworkers (Vistnes and Monheit, 2011), thus there is variation even within state and firm size that we cannot bring in to our models, although it is not clear if this causes any bias. One possibility is that the employee premium shares could be higher than average in firms where low income workers are found, which would lead to more workers finding coverage unaffordable than we predict.

${ }^{20} \mathrm{http://www.bls.gov/news.release/empsit.a.htm,} \mathrm{accessed} \mathrm{August} 2010$.

21 http://healthreform.k_org/SubsidyCalculator.aspx, accessed March 29th 2010. There is a high degree of uncertainty regarding future exchange premiums, such as whether they may be higher than anticipated because of possible adverse selection into exchange coverage. Thus, we kept the KFF premiums in 2014 terms for lack of a CPI for adjustment to 2008 terms and to counteract some of this possible understatement of exchange premiums. The KFF estimates are for a 70 percent actuarial value plan, which is less generous on average than ESI plans. Gabel et al, (2006) show that actuarial values of ESI plans range from $73.4 \%$ to $87.6 \%$ depending on the state. To the extent that exchange plans are lower in actuarial value than ESI plans, there will be less of an incentive to move towards
} 
policy holder, for a "medium" cost region. To calculate the cost of family coverage we obtained the difference between the cost of single coverage and coverage for a family of four and divided that difference by three. We used this resulting number as the cost of an additional family member in the exchange.

An issue we consider in detail in constructing the data set and in later calculations is how the law treats different types of families in the CPS. Even though we focus only on workers for our tables, the incentives for health insurance choices made by these workers are influenced by their family circumstances. For example, families with one worker will face different options under reform than families with two workers. It further matters whether each of the workers has existing ESI coverage, whether that ESI is single or family coverage, whether the workers are employed in large or small firms, in full-time or part-time jobs, and whether the children are already enrolled in Medicaid or Children's Health Insurance Program (CHIP). Medicaid and CHIP (henceforth referred to as CHIP for children's coverage) are potentially very important because the existing eligibility thresholds for children’s public coverage are generally much higher than the adults' threshold even after the Medicaid expansion under the ACA. This has implications for whether a lower income family who considers exchange coverage may find their children to be eligible for CHIP. ${ }^{22}$

exchange coverage. However, Dafny et al (2010) show that consumers value the increased choice they face in exchange coverage to a substantial degree, which may counteract the lower actuarial value for the Silver Plans. The ACA also has provisions to ensure that the actuarial value of exchange plans increases for low income families, to $94 \%$ for families up to $150 \%$ FPL, until it reaches $70 \%$ at $400 \%$ FPL through cost sharing subsidies, thus it is unclear whether the lower actuarial value of exchange plans would affect our results.

${ }^{22}$ Any children who are found eligible for CHIP but not signed up are likely to be provided with CHIP and the remainder of the family would receive exchange coverage. If there are children who are already on public health insurance in the CPS, we assume that they will keep that coverage throughout our calculations. We assume currently fully uninsured or currently fully ESI insured families stay together for health insurance choices and that children not already enrolled in public coverage will not be put into a separate plan. However, we have conducted separate calculations assuming all eligible children will take-up CHIP and we report later in the paper (in Table 4 and footnotes) the sensitivity of results to this extreme assumption. How CHIP eligible children who are not currently enrolled are treated in our calculations could have potential biases in both directions for our final results regarding ESI vs. exchange coverage. Separating the children into one plan could make exchange coverage less desirable 
The structure of the family also matters when calculating employer fines for obtaining exchange coverage. We assume that if a family with two workers obtains a family plan with a subsidy in the exchange, only the main policy holder would trigger a fine for their employer. That is, a secondary worker in the same family who is a dependent under the exchange insurance policy will not trigger their own employer fine since the subsidy is technically received only by the main policy-holder worker in our calculations. If the fine is interpreted to apply to both workers, then this means smaller perceived financial advantages to exchange coverage. However, this provision applies only to families with two full time workers in large firms, and it is likely that the total incomes of these families may make it less likely that they would benefit substantially from exchange subsidies in the first place. We explain in detail these and other assumptions we make about the treatment of family members in Data Set Methods appendix accompanying this paper (http://www.nber.org/data-appendix/w17279). However, there are many possible alternative treatments of families that we have not considered here and ones which are not yet interpreted in the law. ${ }^{23}$

relative to continuing ESI. On the other hand, it could make exchange coverage more desirable for the worker because the children could now have lower out of pocket costs in CHIP than exchange coverage. The effect of this decision on the number of dependents in "no-man's land" in Table 4 is clearer, as being eligible for CHIP will reduce the number of dependents without access to affordable coverage.

${ }^{23}$ To illustrate the complexity of these issues (which are yet to be decided by regulation), consider a specific example. A single low- income mother initially obtains ESI coverage for the family, but her employer increases the employee contribution under the family definition of the firewall that would enable her to be eligible for exchange subsidies for her family. Upon application for exchange coverage, her children are found to be eligible for CHIP, which means that she would essentially be obtaining single coverage in the exchange for herself. She may now no longer qualify for a subsidy for exchange coverage since the applicable definition for obtaining exchange subsidies may now be single coverage affordability for her. If this turns out to be the rule, Equation 1 would suggest that this mother would prefer exchange coverage. But she would actually prefer ESI. To see how sensitive our results are to this possibility we have conducted alternative calculations assuming all children eligible but not signed up for CHIP fully take-up CHIP. Doing so, we find relatively small changes in the distribution of incentives. For example, the number of those with positive financial incentives changes from 9.7 million workers to 9.4 million workers in Figure 1. 


\section{Results}

\section{Financial Incentives Calculations}

Using data on workers from the 2009 March CPS and Equation 1, we calculate the extent to which workers gain or lose financially from switching to subsidized exchange coverage, if they are able to overcome the affordability firewall. We perform these calculations only for workers who are income eligible for exchange subsidies (133 percent to 400 percent of poverty) and are either currently covered by ESI or would be affected by the ACA employer mandate. We take the applicable fines and taxes into account and graph a kernel density plot of the full range of possible annual financial incentives $\left(\left[\left(\mathrm{P}_{\mathrm{f}}+\mathrm{P}_{\mathrm{e}}-\mathrm{F}_{\mathrm{e}}\right)(1-t)\right]-\left(\mathrm{P}_{\mathrm{x}}-\mathrm{S}_{\mathrm{x}}\right)\right)^{24}$ in Figure 1. There are 23,913,307 workers represented in Figure 1's universe. The $\mathrm{X}$ axis shows the dollar amounts calculated from Equation 1, and the $\mathrm{Y}$ axis shows the fraction of the sample corresponding to those dollar values. Summing the area under the graph between certain values allows us to compute the fraction of the sample that stands to gain (or lose) that amount annually by choosing exchange coverage instead of ESI.

Even though all the 23,913,307 workers represented in Figure 1 are eligible for a subsidy based on their income and employment status, ESI coverage is a better financial option for 60 percent of them. This is an indication of the effectiveness of the individual fines and tax penalties in the ACA in reducing the potential crowd out of ESI. The remaining 40 percent of these workers face a financial incentive to obtain exchange coverage. A substantial fraction of this

\footnotetext{
${ }^{24}$ In our calculations, we do not consider the possibility that workers would move from large firms to small firms to avoid the penalty of $\$ 3,000$ each. If this behavior were to occur in the long run, workers would have more financial incentives to move out of ESI than our calculations suggest. We also ignore subsidies available to small firms to offer coverage because of their temporary nature of up to two years and because the full credit of 50 percent of the employer contribution towards coverage (which could be as low as 50 percent of the total, putting the credit as low as 25 percent of the cost of coverage) is available only to very small firms with very low-wage workers (firm size less than 10 workers, average annual wages less than \$25,000), many of whom may be eligible for Medicaid or highly subsidized exchange coverage. The cutoff for Medicaid, 133 percent of the federal poverty level, is currently somewhat less than $\$ 30,000$ a year for adults in a family of four.
} 
population has large positive incentives to forego ESI and obtain a subsidy to purchase exchange coverage; 24.82 percent of the sample stands to gain at least $\$ 2,000$ a year and 11.88 percent stands to gain at least $\$ 5,000$ a year.

\section{ESI and Exchange Coverage under Different Employee Contribution Levels For}

\section{Single and Family Definitions}

We next consider the extent to which workers with financial incentives to obtain exchange coverage would be able to overcome the affordability firewall under the single and family definitions. Figure 2 shows ESI coverage rates in the first of the two graphs, and exchange coverage rates in the second of the two graphs, in the context of all workers in our full sample. The solid line depicts the single definition and the dotted line depicts the family definition, for the full range of possible employee contributions. Although the data presented are for all workers, variation in results from one affordability definition to another and from one employee contribution level to another stem from the workers in families with incomes between 133 and 400 percent of poverty. Table 2 presents the data behind Figure 2 for three different levels of employee contribution shares: the current level, 50 percent and 100 percent of the premium. ${ }^{25}$

Figure 2 shows a flat line indicating that exchange and ESI rates do not vary with employee premium contribution shares, in either the single or the family affordability definitions, until employee contribution shares reach approximately 20 percent. This is because average employee premium contributions for both single and family coverage are low enough that no worker with family income between 133 and 400 percent of poverty breaches the affordability firewall until employee premiums reach approximately 20 percent of total premium costs. Figure

\footnotetext{
${ }^{25}$ The current employee contribution as a percent of the total ESI premium varies in our micro data, thus we only indicate the national average on the graph.
} 
2 and the accompanying Table 2 show a large amount of movement into exchange coverage and out of ESI under the family definition, as employee contributions rise from current levels (on average 20.1 percent for single coverage and 27.5 percent for family coverage), until they reach the 50 - 60 percent of premiums range. As shown in Table 2, ESI coverage rates decline from 72.94 percent (at current levels) to 65.14 percent (at 50 percent employee contributions) and 62.57 percent (at 100 percent employee contributions) under the definition of family affordability. The corresponding increase in exchange coverage rates are 13.02, 20.82 and 23.33 percent, respectively. In contrast, there are only small changes in ESI coverage under the single definition as employee contributions rise from current levels to 50 percent, moving from 74.57 percent to 73.19 percent, respectively. ESI coverage rates decline from 73.19 to 69.97 percent when employee contributions move from 50 percent to 100 percent. This difference in patterns for family vs. single coverage is unsurprising. Even at high levels of cost sharing (such as employees paying half the cost— $\$ 2,193$ —of the average national single premiums of $\$ 4,386$ ), single premiums are affordable for most workers, since those with income lower than 133 percent of poverty are eligible for Medicaid rather than exchange subsidies. ${ }^{26}$ But even at lower levels of cost sharing than 50 percent, family premiums are high enough that ESI employee contributions become unaffordable for many workers.

While one might have expected successively more workers to have both the incentive and the ability to opt for exchange coverage rather than ESI coverage as employee contributions rise under the family affordability definition, the line in Figure 1 flattens out after about the 60 percent employee contribution mark. This is because the marginal family whose coverage is made unaffordable by a further increase in the employee contribution beyond this point has

\footnotetext{
${ }^{26}$ For $\$ 2,193$ to be 9.5 percent of income, the worker's family income would have to be $\$ 23,083$, which places a family of four at less than the Medicaid threshold income of 133 percent of poverty.
} 
relatively higher income. At higher levels of income, exchange subsidies taper off, and the cost of the foregone tax benefit and employer penalties make exchange coverage less attractive even if the affordability criterion has been met. At about 60 percent of the average cost of a family plan, the employee contribution would be roughly $\$ 7,400$, using values from Table 1 . The family whose premium would exceed 9.5 percent of income would earn roughly $\$ 78,000$. This places the family at roughly 370 percent of the poverty line. Thus, the amount of the sliding scale subsidy they would receive is very small relative to the fine of $\$ 3,000$ and the loss of tax benefits for ESI, and ESI is a more attractive option.

Examining the data behind Figure 2 further by firm size and income, Table 2 shows that the fraction of workers who would qualify for exchange coverage is much larger in small firms (fewer than 50 employees) than in large firms. This is expected since small firms do not face any employer penalties and since small firm workers are more likely to live in lower income families. Table 2 also shows that changes in the single premium have little effect on ESI rates for those in families with income in the range of 301 to 400 percent of poverty. But it makes a much bigger difference for lower income families. For workers in families with incomes between 133 and 200 percent of poverty, ESI falls from 61.44 percent (current levels of employee contributions) to 49.08 percent (50 percent), while exchange coverage rises from 28.71 to 41.07 percent. In contrast, changes in the family premium matter across all income groups but continue to matter most for lower income workers. Table 2 shows that changes in the employee contribution to the single premium have little effect on ESI rates or exchange coverage for those workers with incomes in the range 301 to 400 percent of poverty, but make a much bigger difference for workers in lower income families. Exchange coverage rises from 23.67 percent to 32.19 percent for those in the 301 to 400 percent of poverty income range when going from 50 percent to 100 
percent of premiums under the family definition. The corresponding change for those in the 133 to 200 percent of poverty income group is 62.27 percent to 65.70 percent.

While our Figures and Tables thus far have shown fractions of our population of workers, Table 3 shows the relevant weighted numbers of workers with exchange coverage corresponding to Figure 2 and Table 2. When employee premiums remain at their current level, the number of workers who would receive exchange subsidies is 5.8 million under a single affordability rule and 7.1 million under a family affordability rule. When employees pay 50 percent of premiums, the number rises to 7.1 million, and 13.1 million respectively. At 100 percent premium contributions, the numbers rise to 9.9 million and 14.8 million. Even with a 50 percent employee contribution, there is a difference of roughly 6 million in the number of workers who could receive subsidized exchange coverage if the affordability definition is family rather than single.

\section{Ability of Worker' Dependents to Find Affordable Coverage if Single Affordability}

\section{is Adopted}

In Figures 1 and 2 and Tables 2 and 3, we have shown the consequences of selecting the single versus the family definition for workers' ESI and exchange coverage rates. Next, we consider the consequences of adopting the single coverage affordability definition, as currently proposed for implementation, for dependents' ability to access affordable coverage. In these calculations, we focus solely on the subset of workers who have dependents in need of insurance and examine the number that may be caught in a "no-man’s land” with no source of affordable coverage for them. This would happen if the worker is offered affordable single ESI coverage, but unaffordable family ESI coverage. In this case dependents are restricted from accessing subsidies in the exchange, even though they are eligible based on their family income. Thus they face the option of taking unaffordable family ESI or an expensive unsubsidized premium in the 
exchange. ${ }^{27}$ In contrast, if these workers' contributions for single coverage rise to a level that exceeds the firewall, they and their families could obtain subsidies through the exchange.

Figure 3 shows the relationship between levels of the workers' contribution for ESI coverage under the single coverage rule and number of workers who find themselves in "noman's land” with no source of affordable coverage for dependents. The sample in Figure 3 is restricted to workers (with dependents) who have positive financial incentives to access subsidized exchange coverage and are seeking family coverage. Figure 3 is the consequence of two offsetting changes that occur as the employee contribution rate rises. As employee contributions for single and family coverage rise, dependent coverage becomes increasingly unaffordable for workers seeking to insure their families, thus increasing the likelihood of the workers dependents being trapped in no-man’s land. But at the same time the worker's likelihood of having unaffordable single coverage rises, allowing both the worker and his or her family access to the exchanges and an escape from "no-man’s land”. 28

Table 4 presents estimates of the number of workers and dependents who would not be able to find affordable family coverage at current employee contribution shares and at 50 percent and 100 percent of employee premiums if the single definition is used. The Table shows the number of workers with unaffordable family coverage, and the number of workers with unaffordable single coverage. The difference between the two is the number of workers in "noman's land". We also show in the Table the number of dependents corresponding to the number of workers in no-man's land. Appendix Figure 1 shows the two separate changes graphically,

\footnotetext{
${ }^{27}$ Under the Code of Federal Regulations proposal on which hearings are being held in November 2011, these dependents would now be exempt from the individual mandate fine if they were to be uninsured.

${ }^{28}$ In this figure, we restrict the employee contribution to single and family coverage to be set the same, and examine consequences when they are both high vs. when they are both high. A different thought experiment would be to keep contribution levels for family coverage to be the same and increase only single contribution rates. While the incentives created by the single affordability definition is for workers and employees to increase the employee contributions to single coverage, we illustrate what would happen under raised family contributions as well because future rising health care costs may lead independently to a rise in employee contribution levels.
} 
with a dotted line for the number of workers with unaffordable single coverage and a solid line for the number of workers with unaffordable family coverage. As employee contributions rise, family coverage begins to become unaffordable for many families. However, single coverage does not become unaffordable until employee contributions exceed 30 percent. Eventually, as the employee contribution rises, more workers and their families escape "no-man's land" than enter it, and the total number of workers who find themselves in no-man's land falls because they become eligible for subsidies.

Figure 3, Panel A of Table 4, and Appendix Figure 1 show that under single affordability, as many as 2.6 million workers with 7.5 million dependents could find themselves without affordable ESI or exchange health insurance for those dependents even if employee premiums stayed at current levels. Panel A of Table 4 also shows that the number of dependents without affordable ESI or exchange insurance could rise to 16 million if rising health care costs lead employees to pay half of total premiums in the future. But these numbers do not take into account the many currently uninsured children eligible but not signed up for CHIP. Uninsured but CHIP-eligible children have a source of affordable coverage, even though they either do not know of their eligibility, have attempted to enroll but found the process too difficult, or chose not to enroll. Accounting for the availability of CHIP decreases the number of dependents who would be without affordable coverage. If these children do enroll in CHIP, the applicable insurance type for the workers would be single coverage, or coverage for self and spouse. Thus, we produce an alternative set of calculations in Panel B of Table 4 where we assume that all of these uninsured but eligible children will be placed into CHIP, using the 2008 CHIP eligibility rules in each state. 
Comparing the results in Table 4 Panel B to Table 4 Panel A, we see that when workers would need to seek ESI coverage for fewer dependents in Panel B, family ESI will appear unaffordable for fewer workers since the applicable ESI family size will be smaller. In Panel B, the consequence of the single affordability definition will be 1.4 million workers with 4 million dependents who would be without affordable coverage for dependents, even if employee premiums remain at the current level. Panel B further shows that this would be 3.7 million workers with 9.9 million dependents if employee contributions are $100 \%$ of the premium, and 5.8 million workers with 12.7 million dependents if employee contributions are $50 \%$ of employee premiums.

\section{Discussion and Summary}

In this paper we show the importance of two understudied aspects of the ACA: whether the affordability definition refers to single or family coverage and the ability of employers and employees to alter the share of the ESI premium paid by the worker. We illustrate with stylized calculations based on the March 2009 CPS how important this definition could be, depending on what one assumes about how employers and employees set the premium contributions. We first calculate the financial incentives that are relevant for every worker in our sample who may potentially consider the choice between ESI and exchange coverage. These incentives are created by the existence of public subsidies for exchange coverage, and take into account the fines and tax penalties. However, the degree to which workers can act on these potential incentives depend on whether the definition of affordability is family or single coverage, and the level at which employee cost sharing would be set in the future. The higher the level of cost 
sharing, the greater the fraction of these workers whose ESI coverage would be considered unaffordable.

Our stylized calculations illustrate the sensitivity of subsidized exchange coverage and ESI take-up to these two understudied factors that are important for understanding the potential impact of the ACA. We show that under a family definition, relatively small changes in the middle of the cost sharing levels (such as 50 percent of the full premium) could have large consequences for exchange coverage and ESI rates. We also show there is a difficult tradeoff

involved, as setting affordability on the single coverage definition would leave many dependents without any affordable source of coverage. In fact, if single coverage affordability is adopted, close to 6 million workers (and close to 13 million dependents) will be unable to find affordable family coverage even if employee contributions are set in the future to be only half of the total premium.

\section{Limitations, Caveats and Directions for Future Work}

Given the large degree of uncertainty regarding how health care and health insurance markets will evolve in the future, all forecasts of the consequences of the implementation of the ACA will be imprecise. Throughout the paper, we mention relevant assumptions and discuss possible biases that may result if our assumptions are wrong. Some of our assumptions may lead to fewer workers preferring exchange coverage over ESI. For example, if firms and workers are not able to control the passthrough of health insurance costs to wages, this may reduce workers incentives to opt for exchange coverage. Employers may be reluctant to increase employee contributions if the workers who leave ESI to obtain exchange coverage are healthier and lead to increased costs for the remaining workers. In the short run, changes of the types discussed here 
are much less likely to occur than in the long run over many years of adjustment. If exchange coverage is less attractive than ESI coverage, this will also tend to make fewer workers prefer exchange coverage over ESI. However, other assumptions we make may bias our results in the opposite direction. For example, we assume no firms drop health insurance outright, nor do we allow workers to consider moving to small firms, part-time work etc. even in the long run to avoid fines and affordability firewalls. These are all questions that remain to be studied as the ACA is implemented.

Our paper does not provide estimates that are directly comparable to those from CBO or other entities, for several reasons. By abstracting from several realistic details that pertain to factors not central to our work, we conduct the analysis in a hypothetical manner to illustrate the impact of the key factors in the paper — the definition of affordability and the setting of employee contributions for ESI. But our analysis does clearly show that estimates that ignore these potentially different interpretations of the affordable care rule and the flexibility in premium share adjustments they may produce, do not allow consideration of the sensitivity of their ESI and subsidized exchange coverage outcomes to a plausible range of possibilities.

Selecting a definition for the affordability rule involves a difficult tradeoff because while single coverage rules do not leave as much room for employers and employees to change behavior in ways that would reduce ESI coverage rates, they would leave many millions of workers in a "no-man's land" of finding no source of affordable coverage. A valuable next step for policy analysis research in this regard would be to examine how coverage impacts may be affected by these different possible affordability interpretations using more sophisticated analyses, and the assumptions regarding employer and employee responses in premium cost sharing. 


\section{References}

Adamy, J. 2011. “Study Sees Cuts to Health Plans”. Wall Street Journal. June 8.Available at http://online.wsj.com/article/SB10001424052702304906004576371802092308600.html

Abraham, J., and R. Feldman. 2010. "What Will Happen If Employers Drop Health Insurance? A Simulation of Employees’ Willingness To Purchase Insurance In the Individual Market.” National Tax Journal 63, p.191-213.

Commonwealth of Massachusetts. 2011. “The Employer Free Rider Surcharge.” Available at http://www.mass.gov/Eeohhs2/docs/dhcfp/r/pubs/11/Free_Rider_2011.pdf

Congressional Budget Office (CBO) 2010: Letter from CBO Director Elmendorf to Nancy Pelosi. March 20 2010. Available at http://www.cbo.gov/ftpdocs/113xx/doc11379/AmendReconProp.pdf.

Congressional Budget Office (CBO) 2007a: Health Insurance Simulation Model: A Technical Description, (October).

Congressional Budget Office (CBO) 2007b: State Children’s Health Insurance Program. Available at http://www.cbo.gov/ftpdocs/80xx/doc8092/05-10-SCHIP.pdf (May)

Dafny, L., K. Ho and M. Varela. 2010. An Individual Healthplan Exchange: Which Employees Would Benefit and Why? American Economic Review, Papers and Proceedings. 100: 485-489.

Fronstin, P. 2011. "Employment-Based Health Benefits and Taxation. Implications of Efforts to Reduce the Deficit and National Debt” Available at http://www.ebri.org/pdf/briefspdf/EBRI_IB_07-2011_No360_Taxes-HI.pdf

Gabel, J. R. McDevitt, L. Gandolfo, J. Pickreign, S. Hawkins, C. Fahlman. 2006. “Generosity and Adjusted Premiums in Job-Based Insurance: Hawaii is Up, Wyoming is Down.” Health Affairs, 25(3): 832-843.

Graves, J. 2011. “The Optimal Design of Prospective Subsidies for Health Insurance Under the Patient Protection and Affordable Care Act” Harvard University Working Paper, http://people.fas.harvard.edu/ jagraves/optimal_design_111910.pdf

Gruber, J. "The Impacts of the Affordable Care Act: How Reasonable Are the Projections?” NBER Working Paper 17168

Gruber, J. and K. Simon. 2008. “Crowd-out 10 years later: Have recent public insurance expansions crowded out private health insurance?” Journal of Health Economics. V.27. 201-217

Holtz-Eakin, D. and C. Smith. 2010 Labor Markets and Health Care Reform: New Results, May 2010. American Action Forum. www.americanactionforum.org. available at http://americanactionforum.org/files/LaborMktsHCRAAF5-27-10.pdf. 
Kessler, D. 2011” How Health Reform Punishes Work”. Wall Street Journal. Available at http://online.wsj.com/article/SB10001424052748704628404576265692304582936.html

Kolstad, J. and A. Kowalski.2010 "The Impact of Health Care Reform on Hospital and Preventive Care: Evidence from Massachusetts.” October. NBER WP \#16012.

Long, S. and P. Masi. 2008. "How Have Employers Responded to Health Reform in Massachusetts? Employees' Views at the End of One Year," Health Affairs, 27 no.6 w576-583 2008.

McKinsey Quarterly, 2011. "How US health care reform will affect employee benefits”. Available at http://www.mckinseyquarterly.com/Health_Care/Strategy_Analysis/How_US_health_care_refor m_will_affect_employee_benefits_2813

Pizer, S., A. Frakt, and L. Iezzoni. 2011. "The Effect of Health Reform on Public and Private Insurance in the Long Run". SSRN Working paper, available at http://papers.ssrn.com/sol3/papers.cfm?abstract_id=1782210

Simon, K. 2010 Implications of Health Care Reform for Employers: An Analysis of the Patient Protection and Affordable Care Act. Prepared for the Center for American Progress. Available at http://www.americanprogress.org/issues/2010/05/pdf/health_employers.pdf

Sommers, B. and S. Rosenbaum, 2011. "Issues in Health Reform: How Changes in Eligibility May Move Millions Back and Forth Between Medicaid And Insurance Exchanges”. Health Affairs, pp.228-236. February, Vol 30, \#2.

U.S. Senate, 2009. “America’s Health Future Act of 2009” October 19. Calendar no 184., report 111-89. Committee on Finance. Online version available at available at http://www.gpo.gov/fdsys/pkg/CRPT-111srpt89/html/CRPT-111srpt89.htm (accessed August 2011)

Vistnes, J. and A. Monheit. 2011. "The health insurance status of low-wage workers: the role of workplace composition and marital status,” May 2, Medical Care Research and Review. 
Table 1: Illustrating the Importance of Family vs. Single Affordability with Hypothetical Families

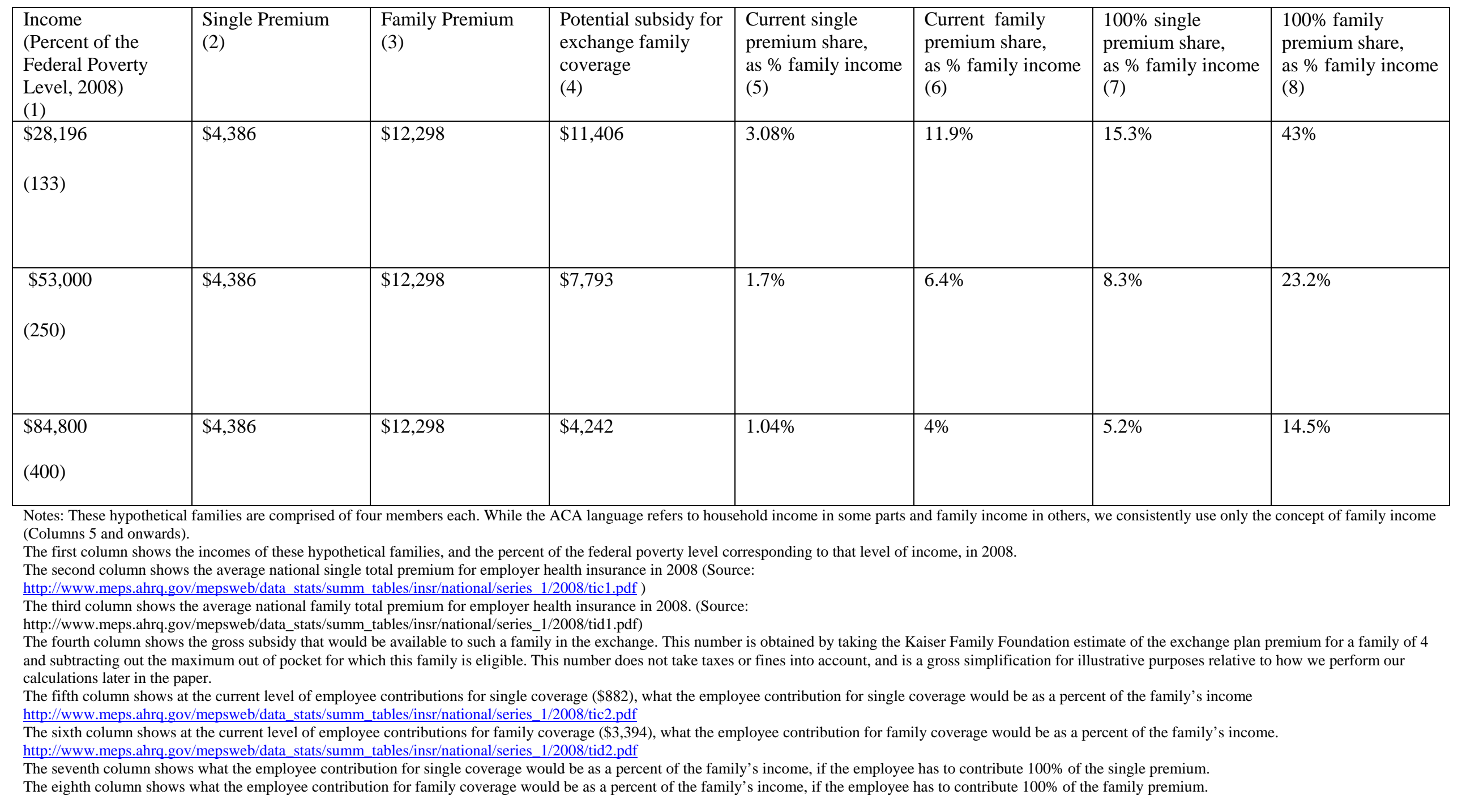




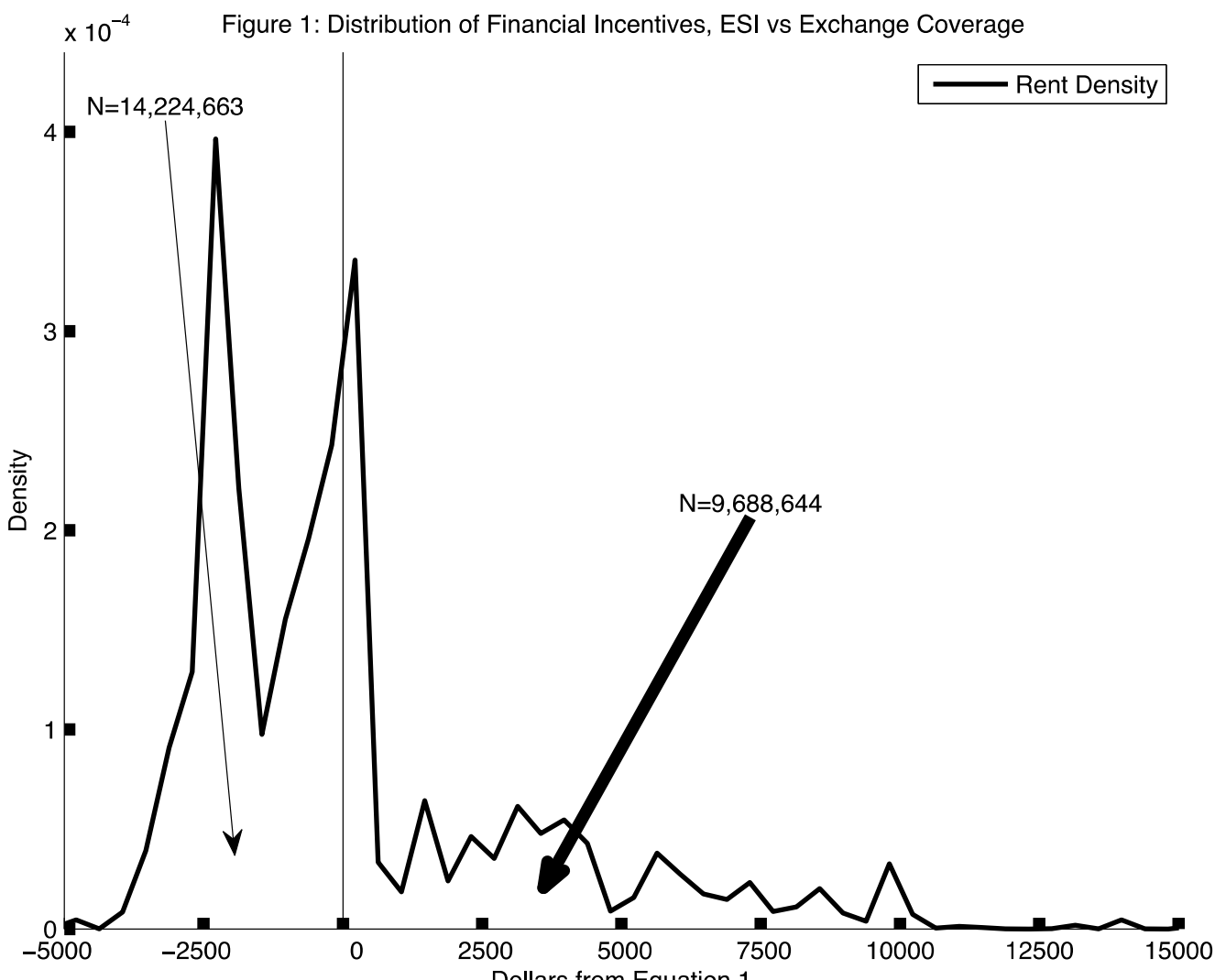

Notes:

Dollars from Equation 1

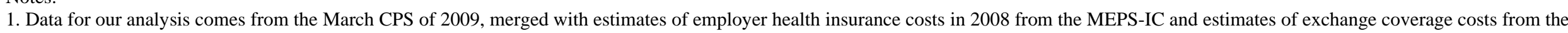

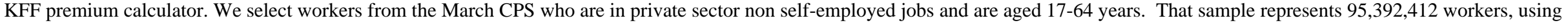
weights.

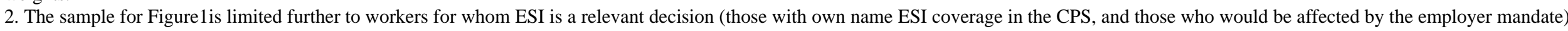
and who live in families with incomes between 133 percent and 400 percent of poverty. This sample represents 23,913,307 workers using weights.

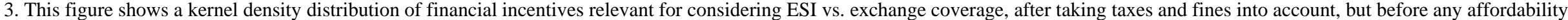

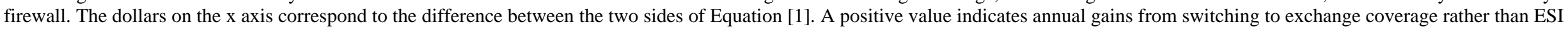

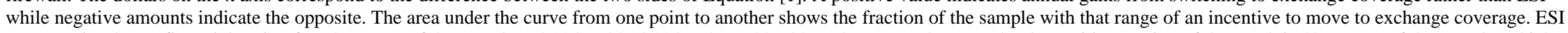

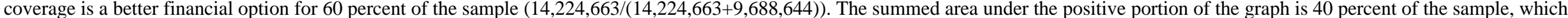

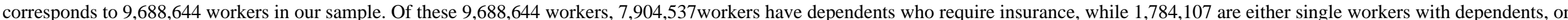
are workers whose dependents are all currently covered by CHIP. 
Figure 2: The Importance of Single vs. Family Affordability

Combined with Different Employee Premium Levels For Exchange Coverage and ESI Rates
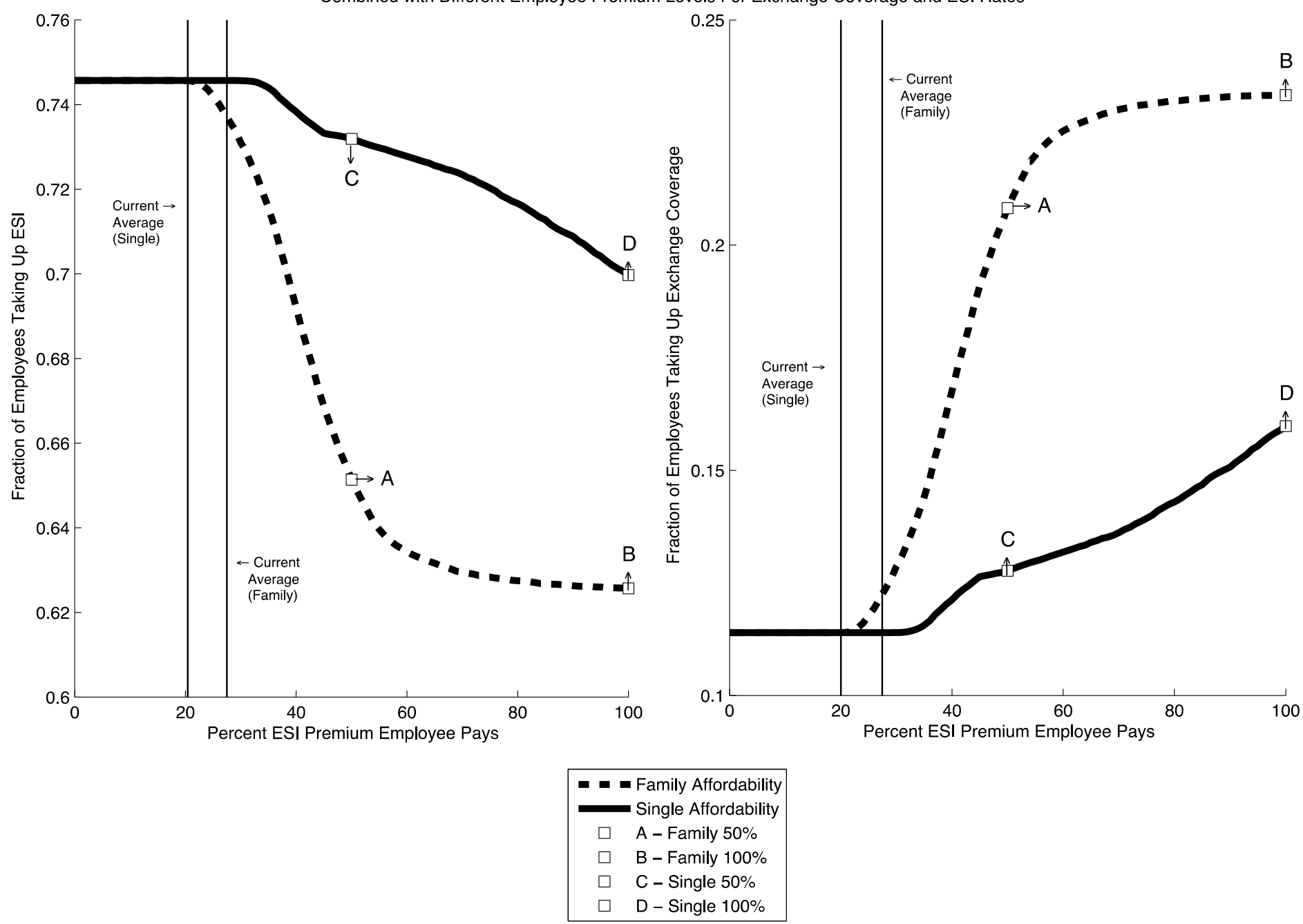

Notes:

1. See Note 1 under Figure 1.

2. The sample for this Figure consists of all workers in our data set (which represents 95,392,412 workers using weights, by note 1 to Figure 1).

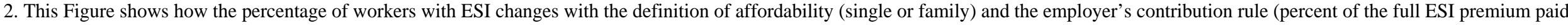

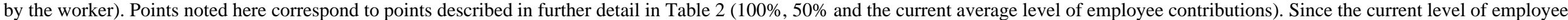

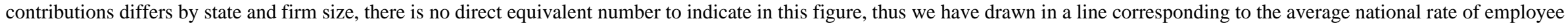
contributions for single and family coverage. 


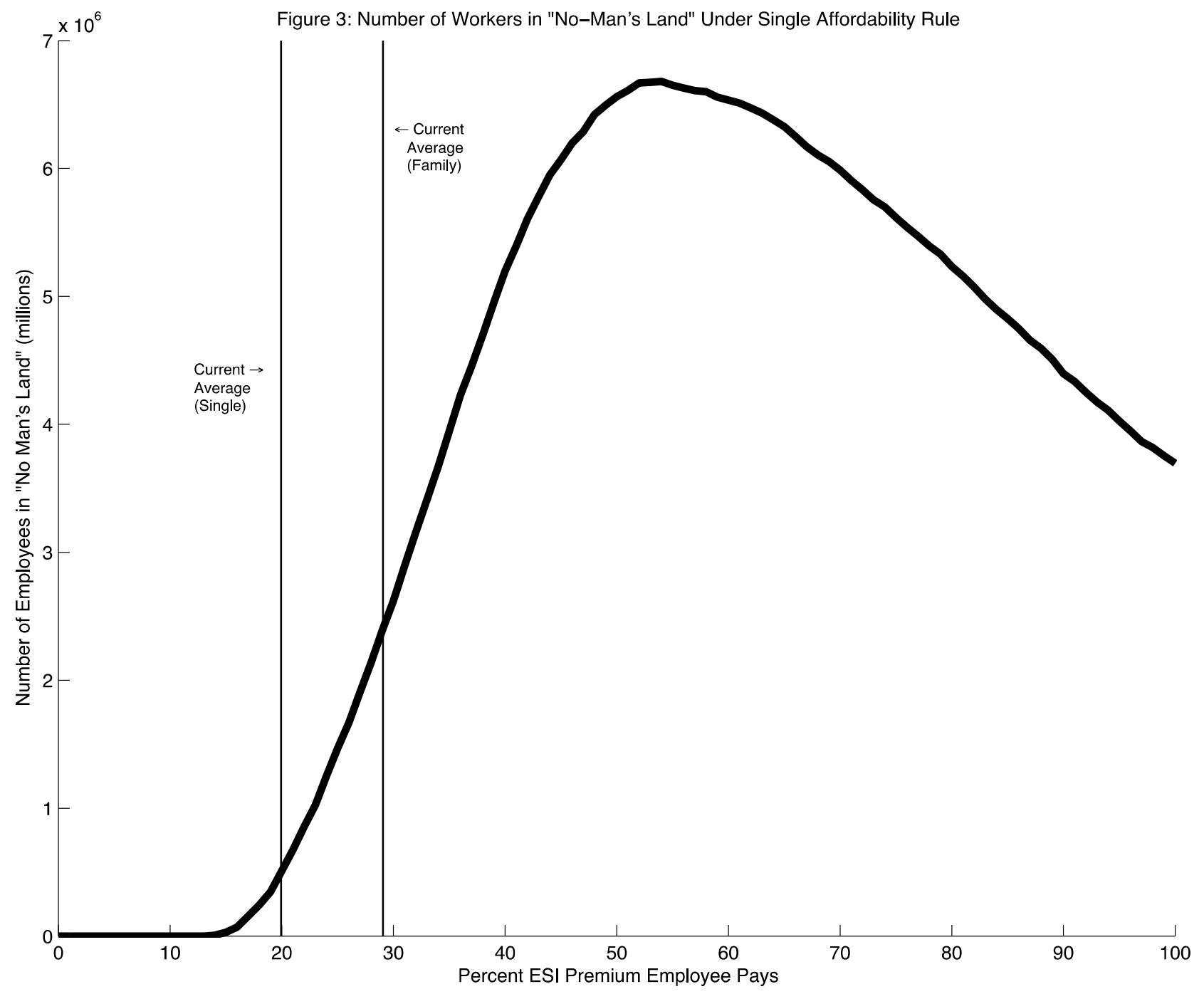

Notes:

1. See Notes to Figure 2 .

2. This Table shows the points indicated on Figure 2 corresponding to employee cost sharing of $100 \%, 50 \%$ and the current level of employee contributions. We show only insurance rates for the income ranges that are eligible for subsidies. 
Table 2: Percent of Workers Insured, by Firm Size, and Income Category.

By Single and Family Affordability Definitions, By Level of Employee Premium Adjustment

\begin{tabular}{|c|c|c|c|c|c|c|c|c|c|c|c|c|c|}
\hline & & \multicolumn{6}{|c|}{ Single Affordability } & \multicolumn{6}{|c|}{ Family Affordability } \\
\hline & & \multicolumn{2}{|c|}{$\begin{array}{c}\text { Current } \\
\text { Premiums } \\
\end{array}$} & \multicolumn{2}{|c|}{$50 \%$ Premiums } & \multicolumn{2}{|c|}{ 100\% Premiums } & \multicolumn{2}{|c|}{$\begin{array}{c}\text { Current } \\
\text { Premiums } \\
\end{array}$} & \multicolumn{2}{|c|}{$50 \%$ Premiums } & \multicolumn{2}{|c|}{ 100\% Premiums } \\
\hline & & ESI & Exchange & $\overline{E S I}$ & Exchange & $\overline{E S I}$ & Exchange & $\overline{\text { ESI }}$ & Exchange & ESI & Exchange & ESI & Exchange \\
\hline \multirow{3}{*}{$\begin{array}{l}\text { Percent } \\
\text { By Firm Size }\end{array}$} & \multirow{3}{*}{$\begin{array}{l}\text { Small Firm } \\
\text { Large Firm }\end{array}$} & 74.57 & 11.39 & 73.19 & 12.77 & 69.97 & 15.98 & 72.94 & 13.02 & 65.14 & 20.82 & 62.57 & 23.33 \\
\hline & & 56.37 & 24.17 & 55.56 & 24.98 & 52.60 & 27.95 & 54.88 & 25.66 & 49.51 & 31.04 & 45.90 & 34.64 \\
\hline & & 83.73 & 4.96 & 82.06 & 6.62 & 78.71 & 9.96 & 82.04 & 6.65 & 73.02 & 15.68 & 70.96 & 17.64 \\
\hline \multirow{3}{*}{$\begin{array}{l}\text { By Income Ranges } \\
\text { of the Federal } \\
\text { Poverty Level }\end{array}$} & \multirow{3}{*}{$\begin{array}{l}133-200 \\
201-300 \\
301-400\end{array}$} & 61.44 & 28.71 & 49.08 & 41.07 & 33.36 & 56.78 & 50.99 & 39.17 & 27.89 & 62.27 & 24.45 & 65.70 \\
\hline & & 75.75 & 18.61 & 74.85 & 19.51 & 65.47 & 28.85 & 72.35 & 22.01 & 48.44 & 45.94 & 43.45 & 50.85 \\
\hline & & 82.84 & 13.27 & 82.84 & 13.27 & 82.09 & 14.03 & 82.68 & 13.44 & 72.44 & 23.67 & 63.74 & 32.19 \\
\hline
\end{tabular}

3. $\quad$ See Notes to Figure 2.

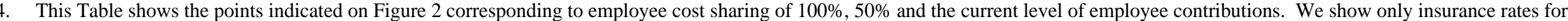
the income ranges that are eligible for subsidies.

\section{Table 3}

Number of Workers With Exchange Subsidized Coverage

\begin{tabular}{l|ccc}
\hline $\begin{array}{l}\text { Employee } \\
\begin{array}{l}\text { Contribution } \\
\text { Level }\end{array}\end{array}$ & Single Affordability & $\begin{array}{c}\text { Family } \\
\text { Affordability }\end{array}$ & Difference \\
\hline Current & $5,803,944$ & $7,092,138$ & $-1,288,195$ \\
$50 \%$ & $7,120,189$ & $13,109,899$ & $-5,989,710$ \\
$100 \%$ & $9,870,451$ & $14,748,991$ & $-4,878,541$ \\
\hline
\end{tabular}

Notes: See notes to Figure 2. 
Table 4: Number of Workers and Number of Dependents in "No-Man's Land"

Under Single Affordability Definitions

Panel A: Assuming No Increase in Take-up of CHIP

\begin{tabular}{c|cccr}
\hline $\begin{array}{c}\text { Employee } \\
\text { Level }\end{array}$ & $\begin{array}{c}\text { Number of Workers } \\
\text { with Unaffordable } \\
\text { Family Coverage }\end{array}$ & $\begin{array}{c}\text { Number of Workers } \\
\text { with Unaffordable } \\
\text { Single Coverage }\end{array}$ & $\begin{array}{c}\text { Number of } \\
\text { Workers in } \\
\text { "No-Man's } \\
\text { Land" }\end{array}$ & $\begin{array}{c}\text { Number of } \\
\text { Dependents of } \\
\text { Workers in "No- } \\
\text { Man's Land" }\end{array}$ \\
\hline $\begin{array}{c}\text { Current } \\
50 \%\end{array}$ & $2,561,827$ & 0 & $2,561,827$ & $7,542,726$ \\
$100 \%$ & $7,951,141$ & 390,401 & $6,560,740$ & $16,063,536$ \\
\hline
\end{tabular}

\section{Panel B: Assuming Full Take-up of CHIP}

\begin{tabular}{c|cccr}
$\begin{array}{c}\text { Employee } \\
\begin{array}{c}\text { Lontribution } \\
\text { Level }\end{array}\end{array}$ & $\begin{array}{c}\text { Number of Workers } \\
\text { with Unaffordable } \\
\text { Family Coverage }\end{array}$ & $\begin{array}{c}\text { Number of Workers } \\
\text { with Unaffordable } \\
\text { Single Coverage }\end{array}$ & $\begin{array}{c}\text { Number of } \\
\text { Workers in } \\
\text { "No-Man's } \\
\text { Land" }\end{array}$ & $\begin{array}{c}\text { Number of } \\
\text { Dependents of } \\
\text { Workers in "No- } \\
\text { Man's Land" }\end{array}$ \\
\hline Current & $1,371,445$ & 0 & $1,371,445$ & $4,017,351$ \\
$50 \%$ & $6,153,640$ & 370,026 & $5,783,614$ & $12,657,387$ \\
$100 \%$ & $7,301,848$ & $3,654,658$ & $3,647,189$ & $9,881,903$ \\
\hline
\end{tabular}

1. $\quad$ See notes to Figure 3

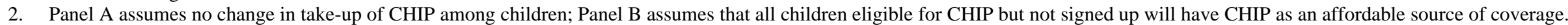

3. The column for number of workers in Panel A corresponds to Figure 3. The number of dependents represents those other than the worker. 


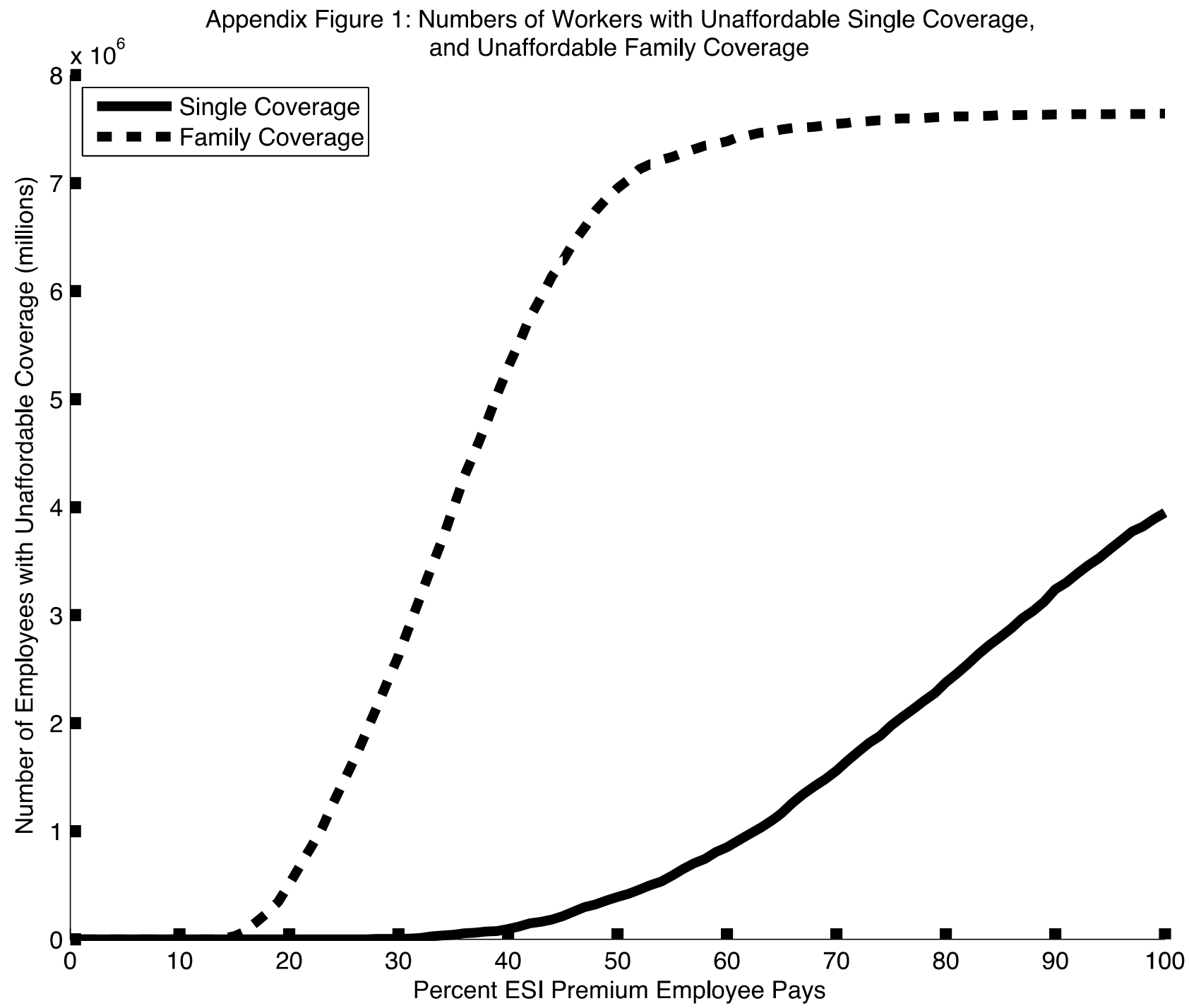

Note:

1.See notes to Figure 3.

2. Being in "no-man's land" is defined as having affordable single coverage but unaffordable family coverage. When employee contributions are approximately $15 \%$, some workers' family coverage becomes unaffordable. When employee contributions are approximately 35\%, some workers' single coverage becomes unaffordable, allowing them to escape "no-man’s land”. Thus, this Figure shows the two separate forces behind the graph in Figure 3. 